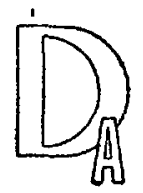

ESTUDIOS

\title{
PRECISIONES SOBRE ORGANIGRAMAS
}

65.012 .32

Por LUIS BLANCO DE TELLA

Sumario: 1. ¿Qué debe destacarse gráficamente en un organigrama?-2. El abuso del organtgrama AFNOR.-3. Las ramificaciones anormales.-4. El organigrama se recarga con epigrafes o recuadros de valor genérico. - 5. Exceso de relaciones secundarias.-6. Presencia de aspectos no formales en el organlgrama.-7. Conclusiones.

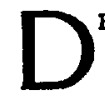

E algunos años a esta parte puede constatarse en nuestra Administración pública un empleo cada vez más frecuente de los organigramas como medio de expresión de sus estructuras formales. Lo que antes era un hecho insólito se ha convertido hoy en práctica corriente. Es cierto, sin duda, que en muchos organismos no ha llegado a fructificar aún ninguna tentativa en este sentido, sea porque la entidad carece de una verdadera estructura representable o bien porque, como dice Riccardi, sus elementos directivos tienden constitucionalmente a la desorganización cientifica (1). Pero, dejando al margen estos casos, la generalización de los organigramas es una realidad que, a mi juicio, supone un avance positivo.

(1) Riccand, Riccardo: La dinámioa de la dirección, Rialp, Madrid, 1959, página 99. 
El simple levantamiento de un organigrama impone una actitud analitica en el que lo elabora y en los que lo examinan, al paso que destaca las anomalias y puntos oscuros de la estructura reflejada (amorfismo estructural, desequilibrio, indeterminación de rango, imprecisión de las líneas de autoridad, excesos o reducciones anormales en la esfera de control, etc.). Desde este punto de vista los organigramas pueden contribuir a un replanteamiento de fondo de la estructura de la organización, ventaja que por sí sola justificaria su aplicación en nuestros organismos públicos.

Pero, además de ello, los mencionados gráficos pueden constituir un medio informativo de primer orden, siendo precisamente los organigramas elaborados con tal finalidad los que han de cuidarse de manera especial si se quiere evitar que, lejos de informar, confundan u obliguen a descifrar lo que podia haberse expresado de forma inequívoca.

Personalmente estimo que la falta de criterios uniformes en esta materia, unida en ocasiones a la fantasía individual, han dado lugar a numerosos errores y curiosas desviaciones que, en caso de extenderse y consolidarse, podrían terminar afectando a la utilidad práctica de los organigramas. Esta observación sirve de fundamento a las presentes notas, encaminadas a señalar algunos puntos débiles advertidos reiteradamente a lo largo de los últimos años.

La subsanación de los defectos gráficos que se apuntan requeriria, como primera medida, una mayor intervención de las unidades de Organización y Métodos en la preparación de los organigramas. Tales unidades, obviamente, deben asumir la función de elaborar los que se preparen para su inclusión en publicaciones oficiales tales como Memorias, guias informativas y otras semejantes. Con ello se evitaria la multiplicidad inconveniente de variedades gráficas, más ostensible aún cuando distintos organigramas aparecen incluidos en una misma colección.

Por otro lado sería igualmente deseable la adopción de criterios uniformes por parte de las citadas unidades de Organización y Métodos. En efecto, la observación del trabajo realizado en este campo por distintas oficinas especializadas revelan la aplicación de soluciones distintas en el tratamiento de problemas idénticos, con las consiguientes dificultades de interpretación.

Pasamos pues al examen de las anormalidades más destacables y frecuentes en nuestra práctica administrativa. 
1. ¿Qué debe destacarse gráficamente en un organigrama?

Como es sabido, todo organigrama suele presentarse como un conjunto de figuras geométricas enlazadas por líneas. Aquéllas representan los elementos orgánicos -unidades o puestos-y éstas las relaciones establecidas entre los mismos. La cuestión estriba en determinar si ha de concederse mayor relieve gráfico al trazado de las relaciones o al de las figuras. Acudiendo a un ejemplo, se trata de decidir razonablemente si los organigramas han de ser elaborados en la forma que muestra la figura 10 , por el contrario, como se indica en la figura 2.

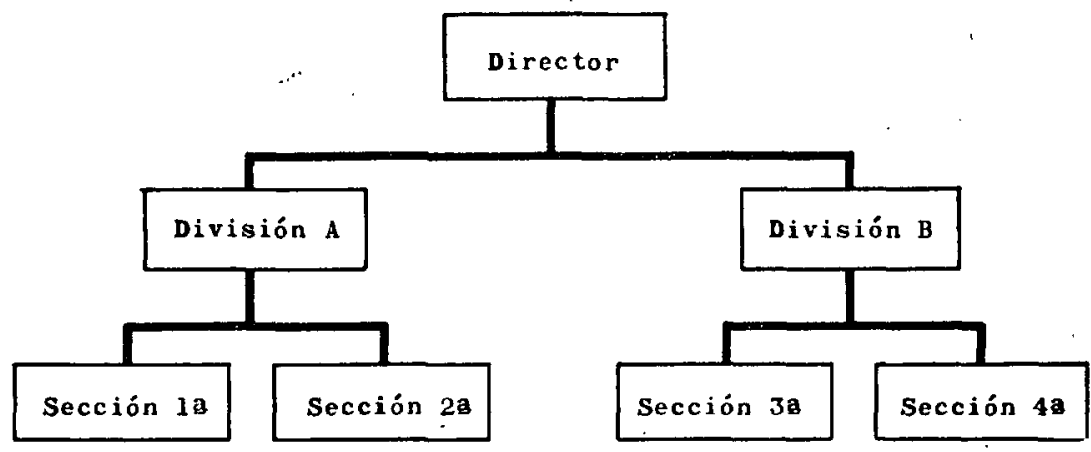

FIGURA 1

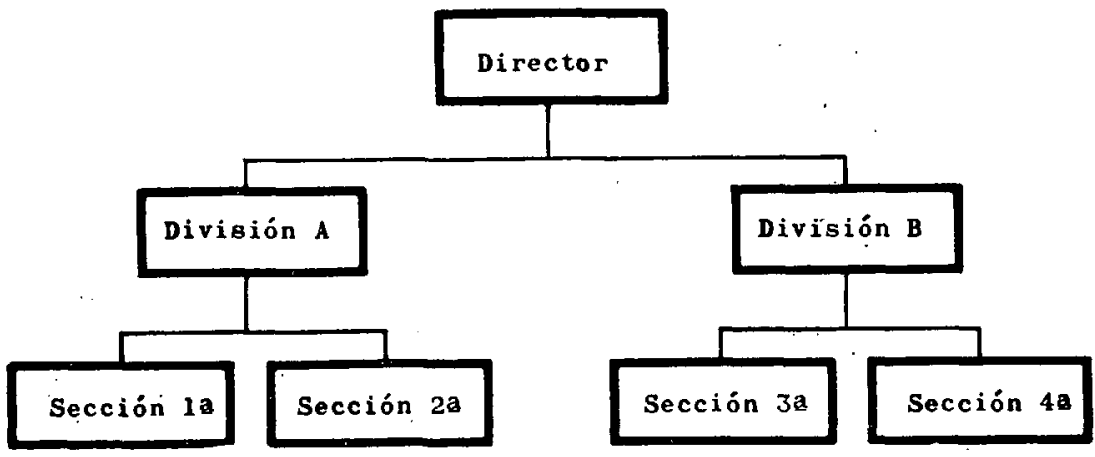

FIGURA 2 
En este punto, creo que la solución resulta obvia. Si se desea conceder un tratamiento gráfico preferente a alguno de los dos elementos citados, lo que ha de destacarse con trazo grueso será aquello que resulte indispensable en la construcción del organigrama. $Y$ lo imprescindible $\mathfrak{\in n}$ un organigrama cualquiera es el entramado de la relación principal de autoridad y responsabilidad, y no las figuras geométricas que lo adornan.

Un organigrama puede, incluso, prescindir totalmente de las figuras, pero no puede concebirse sin las líneas, ya que son éstas, precisamente, las que materializan la estructura formal de la organización. En estas condiciones no parece justificado operar, como es frecuente, del modo que recoge el gráfico 2. Tales representaciones encierran posiblemente una supervaloración de factores subjetivos. Por el contrario, un organigrama sin figuras no sólo ha de estimarse admisible, sino que puede constituir además la solución adecuada para evitar los pequeños problemas que nacen en la práctica al interpretar la superficie concedida a cada posición como un signo externo de su importancia relativa. Los organigramas elaborados del modo que se indica en la figura 3 son normales en la Administración inglesa $\mathrm{y}$ han sido recomendados por la unidad central de Organización y Métodos de dicho país (2).

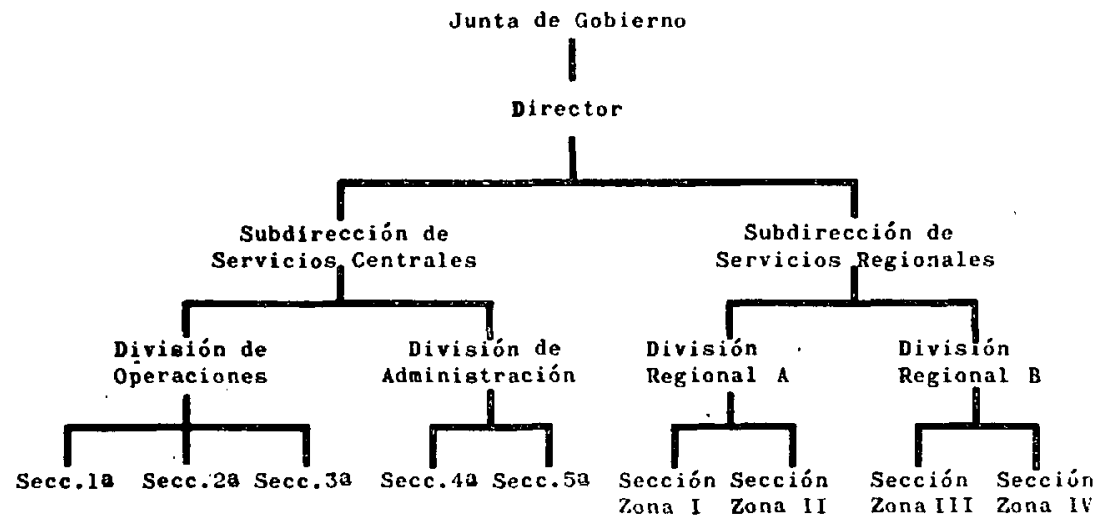

FITGURA 3

(2) Organisation charts and lists of auties, H. M. Treasury O. \& M. DIvision, Londres, 1954. 


\section{El abuso del organigrama AFNOR}

Ignoro las razones por las que el organigrama inspirado en la norma francesa NF Z $12001, y$ conocido corrientemente como organigrama $A F N O R$, se ha extendido en la Administración española hasta el punto de que, prácticamente, es el único que se confecciona.

Esta especial disposición gráfica, que generalmente aparece adulterada con aditamentos que la norma citada no prevé, debería reservarse exclusivamente para representaciones elaboradas con fines analiticos y limitadas a sectores orgánicos de mediana o pequeña envergiadura. Tales representaciones, en la práctica, son por añadidura las menos frecuentes.

No alcanzo a ver las ventajas que supone reflejar la estructura de un Ministerio o de una Dirección General, con fines meramente informativos, acudiendo a esta original forma de trazado. Por el contrario, las diflcultades de lectura que se derivan de la escritura de epígrafes o denominaciones en vertical son bien patentes, como pueden serlo también las que produce un plegado en acordeón que, en ocasiones, parece interminable.

S1 se piensa que el organigrama en cuestion, al utilizar recuadros verticales, determina un ahorro de espacio, ha de advertirse que no siempre ocurre así. Existen, en efecto, otras posibles formas de representar gráficamente la estructura de la organización que, en muchos casos, requieren menor superficie que el organigrama AFNOR, resultando además más claras y manejables.

Por lo pronto, la práctica observada en los organismos de la Administración francesa, tiende a restringir el uso del citado gráfico (3), pudiendo constatarse en cambio un empleo creciente de los organigramas ramificados en horizontal, llamados también orlogramas, según la denominación propuesta por Lobsteln. En mi opintón, sin necesidad de acudir a los organigramas horizontales, cuyo trazado puede requerir una superficie excesiva en altura, las representaciones más claras y compactas se alcanzan a través de un desarrollo mixto, es

(3) V. M. Chassaing: «La représentation graphlque des structures hiérarchiques", en $O$. et $M$. Bulletin, núm. 6, Servlce Central d'Organisation et Méthodes. París, oct.-dec., 1962. pp. 21 y ss. 
decir, en vertical para los primeros niveles y en horizontal para los escalones de base.

Las figuras 4 y 5 permiten comparar un trazado ajustado en principio a la norma francesa NF $Z 12001$ con un esquema de ramificación mixta y decidir acerca de las ventajas e inconvenientes respectivos.

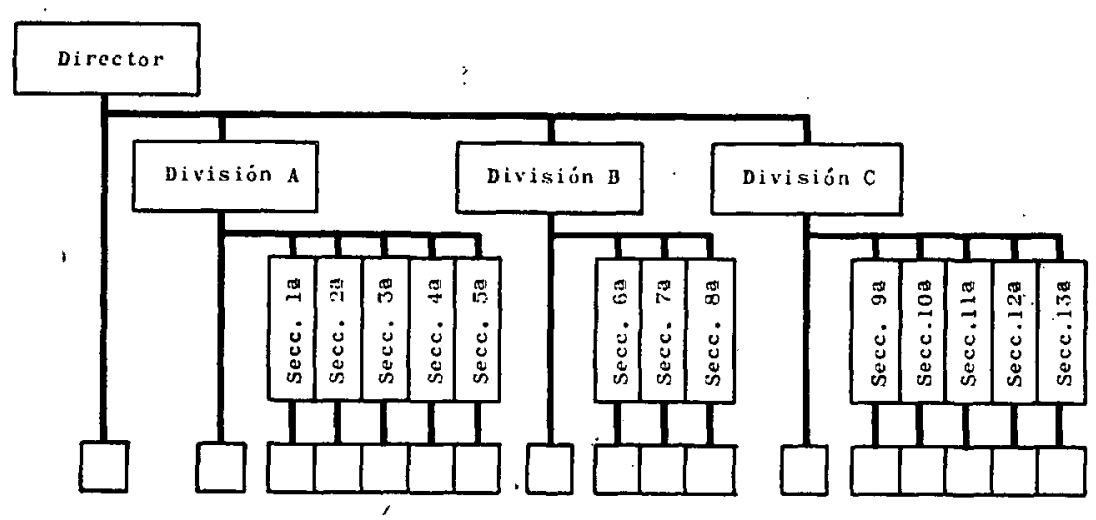

FIGURAA 4

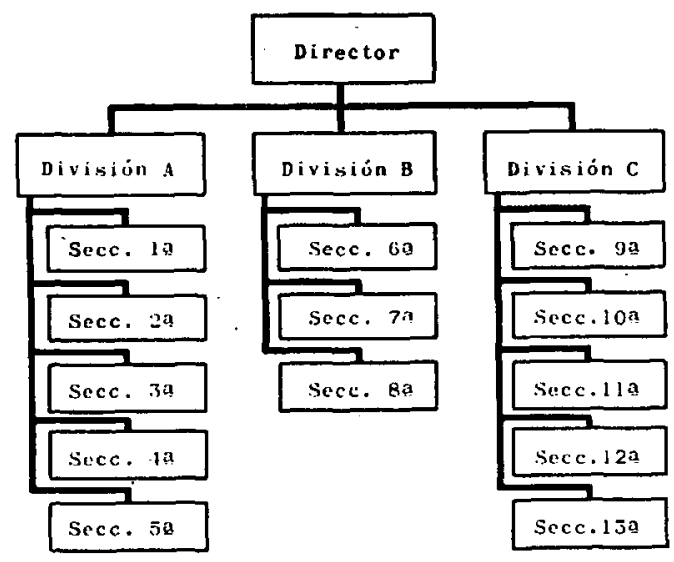

FIGURA 5 


\section{Las ramificaciones anormales}

Con frecuencia pueden contemplarse organigramas en los cuales el trazado de las relaciones aparece concebido de tal forma que su interpretación puede conducir fácilmente a las conclusiones más peregrinas. Ejemplos de tales aberractones gráficas son las que a continuación se recogen.

\subsection{POSICIÓN INCORRECTA EN LAS UNIDADES DE APOYO}

Cuando varias asesorias o elementos semejantes, llamados a prestar asistencia a un determinado dirigente, se representan como muestra la flgura 6, parece que se quiere expresar que cada uno de ellos, excepto el que ocupa la posicion inmediata a aquél, ejerce sus funclones a través de los que le preceden. Asi, en la figura 6, habría

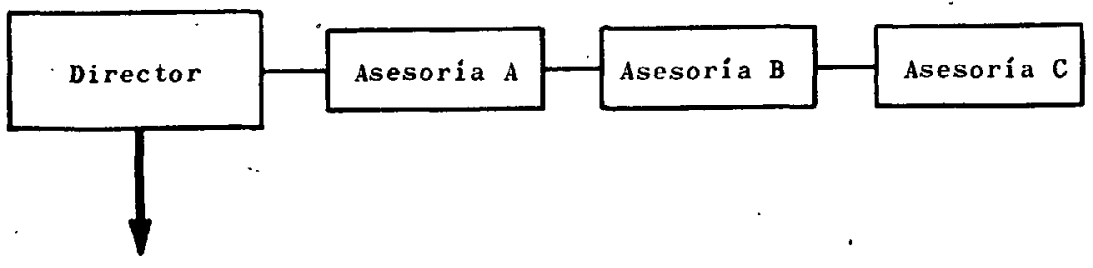

FIGURA 6

que pensar que las asesorias A y B actúan como filtros depuradores de los dictámenes de la asesoria C. Esta interpretación se evita procediendo como indica la figura 7. La línea consultiva debe representarse por medio de un trazo fino.

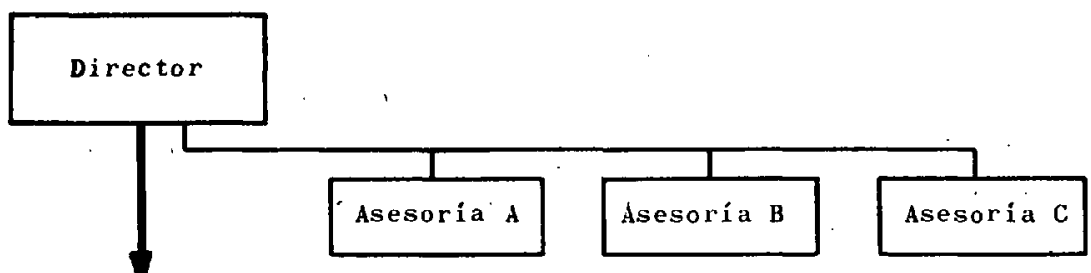

FTGURA 7 


\subsection{RELactones SIN RAMTFICAR EN EL SECTOR DE IfNEa}

En el mismo defecto que se acaba de anotar con relación a las untdades de staff se incurre también al representar el sector de línea. La estructura piramidal propia de este sector se transforma gráficamente en una especie de fila india jerárquica. La interpretación más lógica de estos curiosos «organigramas» (figura 8) consistiria en

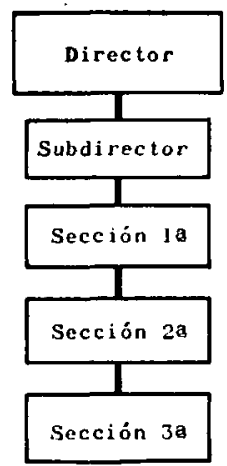

FIGURA 8

pensar que cada elemento depende inmediatamente del anterlor e indirectamente de todos los que le preceden hasta alcanzar el vértice. El problema, en este caso, resulta tan simple que no parece necesario señalar su solución.

\subsection{Pluralidad de IfNeas de autoridad partiendo de una MISMA JEFATURA}

Cuando se olvida que todas las unidades responsables directamente ante una misma jefatura deben quedar ligadas a ésta por medio de ramificaciones de una sola línea común, suele ocurrir que 
el organigrama se presente en la forma que refleja la figura 9. Esta abundancia de íneas que parten de la posición directiva resulta inmejorable para acentuar la tendencia de las unidades administrativas a actuar como compartimentos estancos. Cada elemento subordinado dispone de su relación exclusiva y reservada. Con ello, lejos de concebirse la jefatura como algo unitario, parece desdoblarse en tantas porciones como lineas nacen de la misma.

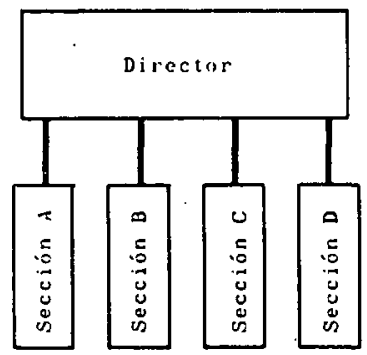

FIGURA $\theta$

\subsection{LA LINNEA DE AUTORIDAD CAMBIA INESPERADAMENTE DE SENTIDO}

Suele ocurrir en algunas ocasiones que la línea de autoridad (forzosamente descendente en los organigramas verticales), remonta bruscamente su curso normal para desembocar en una posición determinada que se coloca a la misma altura que el dirigente (figura 10). Este fenómeno se produce especialmente en aquellos casos en que la persona que ocupa una segunda jefatura tiene asignada la misma categoría que corre̊sponde al titular de la jefatura superior. En todo caso se trata de un error gráfico nacido de la confusión de dos nociones distintas: el rango administrativo correspondiente a cada posición orgánica y la categoria asignada ad personam. Obviamente un organigrama no es un medio de expresar información relativa a las personas, sino simple exposición del dispositivo orgánico de la entidad. 


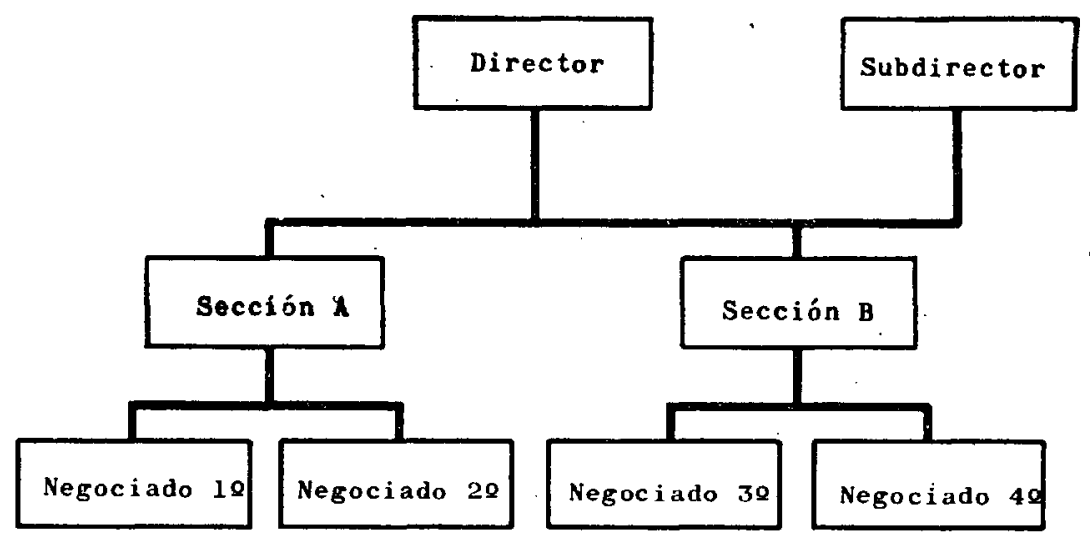

FIGURA 10

\subsection{LA LINEA DE AUTORIDAD SE DEBILITA PROGRESIVAMENTE}

Una de las curiosidades más notables que he podido contemplar en materia de organigramas consiste en trazar la linea principal de autoridad y responsabilidad de modo que vaya adelgazando a medida que la ramificación atraviesa los distintos niveles progresando hacia la base (figura 11).

Aunque no es fácll determinar el significado exacto de este particular trazado, parece que con ello quiere destacarse la posición que corresponde a los elementos de cada nivel dentro de la estructura de la organización. Es evidente, sin embargo, que dicho extremo queda puesto suficientemente de relieve por la misma construcción del gráfico, sin necesidad de acudir a artificios que pueden inducir a confusión sobre la naturaleza de la línea de autoridad.

En efecto, siendo normal reservar el trazado fíno para representar las relaciones de contenido funcional, podría pensarse a la vista de la figura 11 que las jefaturas del último nivel sólo tienen atribuida autoridad de dicha naturaleza sobre sus subordinados. Con el trazado que se examina parece, por tanto, que se trata de reflejar una transformación paulatina de la relactón de autoridad, que co- 


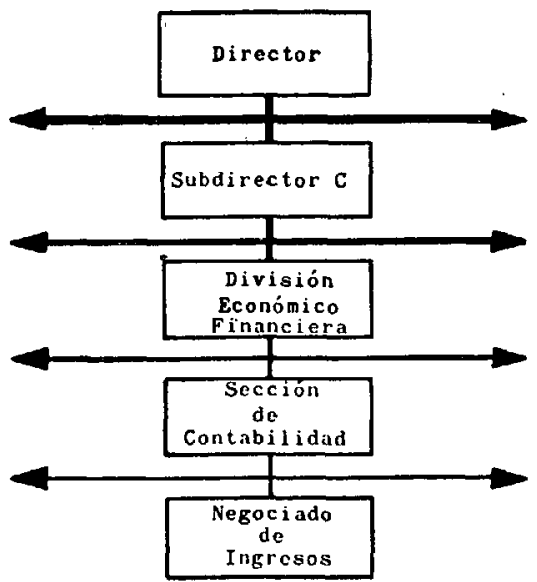

FIGURA 11

mienza slendo principal o de linea y termina siendo funcional. No es necesario decir que la construcción correcta consiste en utilizar el mismo trazado para representar vinculos de una misma clase. En otras palabras, no es la cantidad, sino la naturaleza de la autoridad lo que han de poner de maniflesto las líneas llamadas a representarla.

\section{El organigrama se recarga con epígrafes o recuadros de valor genérico}

No es dificil encontrarse organigramas en los que se utilizan ciertos recuadros para recoger conjuntamente todos los elementos de un determinado nivel, apareciendo después esos mismos elementos individualizados en el escalón inmediato inferior (figura 12). El resultado es que el gráfico aparece provisto de un número de niveles mayor del que en la realidad existe. Merced a este ingenioso recurso, una estructura elemental puede producir la apariencia de un esquema formal altamente elaborado y complejo. 


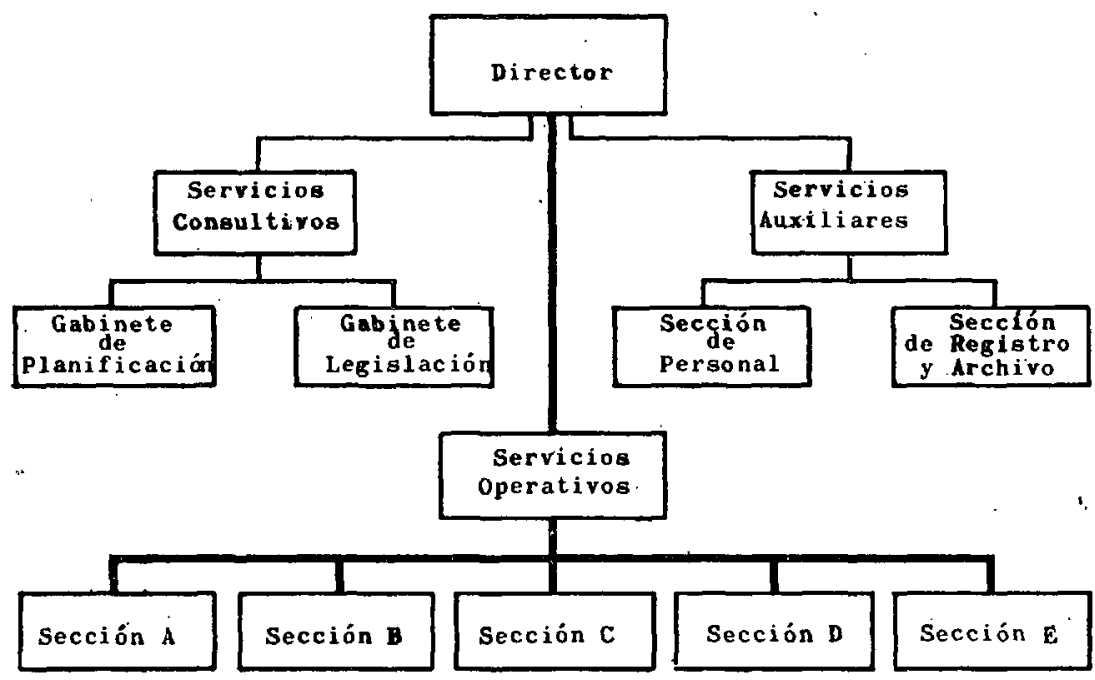

FIGUTRA 12

En este punto, sin llegar a proscribir por completo el empleo de recuadros genéricos, creo que éstos sólo pueden ser válldamente utilizados cuando con ellos quiere indicarse la existencia de varias unidades semejantes que no se representan separadamente dentro del mismo gráfico. Dicho de otra forma, una figura o epígrafe de valor genérico no debe nunca desarrollarse en sus elementos componentes.

\section{Exceso de relaciones secundarias}

A juzgar por su apariencia, ciertos organigramas parecen elaborados con el fírme propósito de recoger en su totalidad las distintas relaciones establecidas entre los elementos que integran la estructura de la entidad. En estos casos parece partirse de la idea preconcebida de que un organigrama, si no es completo, es defectuoso. El resultado suele ser un enmarañado laberinto ante el cual la abstención representa la postura más prudente (figura 13).

Para resolver la cuastión planteada en este lugar debe determinarse previamente la finalidad que el gráfico persigue. Si esta es 


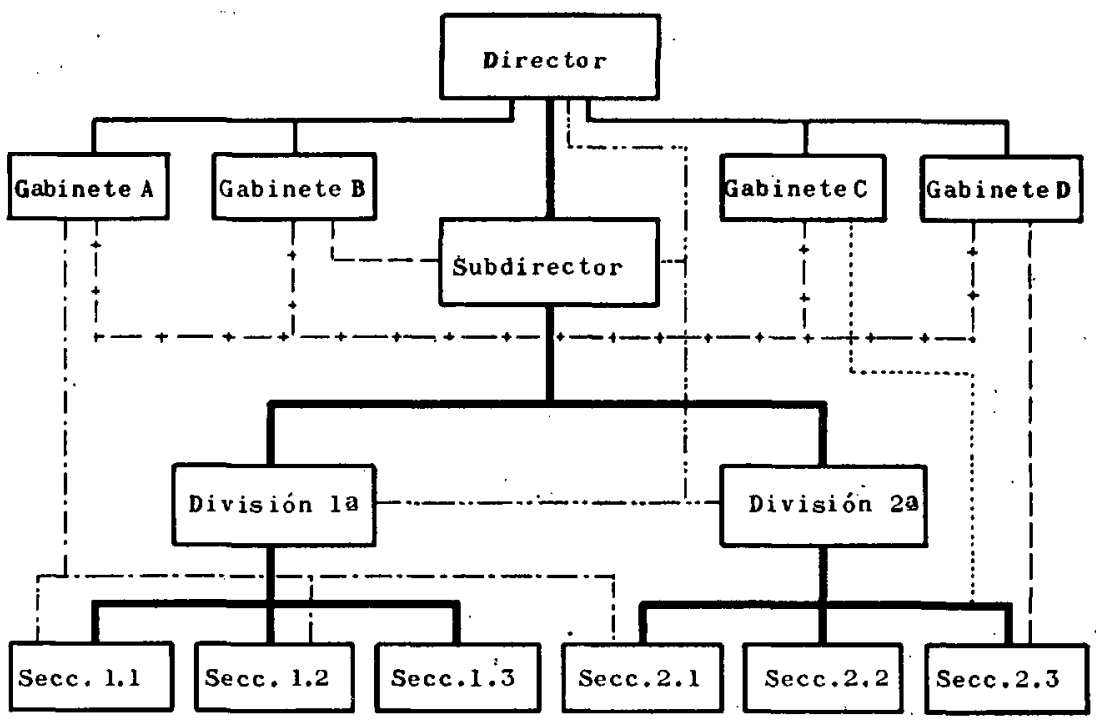

FIGURA $13^{*}$

meramente informativa, el organigrama debe limitarse a recoger la estructura de la organización en sus líneas fundamentales (vínculo principal de autoridad-responsabilidad y elementos de cada nivel), omitiendo todas las relaciones secundarias o aspectos de detalle cuya presencia afecta directamente a la claridad de la representación (relaciones funcionales, expresión numérica de efectivos, composición de comités, relaciones horizontales de coordinación, etc.). A mi juicio, un organigrama informativo no tiene por qué ser completo. El ideal, en este aspecto, ha de ser una representación tal que no requiera leyenda o explicación alguna.

Por el contrario, cuando el organigrama se elabora con fines analíticos y está, en consecuencia, destinado a ser manejado solamente por la persona o grupo de personas que intervienen en un estudio de organización, es aconsejable recoger toda la informactón que sea susceptible de representación gráfica, ya que cualquler dato puede tener relevancia para el desarrollo del análisis. 


\section{Presencia de aspectos no formales en el organigrama}

Puede ocurrir en ciertas ocasiones que los organigramas incorporen aspectos de puro hecho incompatibles o contradictorios con la estructura oficial de la entidad. Asi, por ejemplo, la estructura representada en la figura 14 podría corresponder a un organismo cuyo

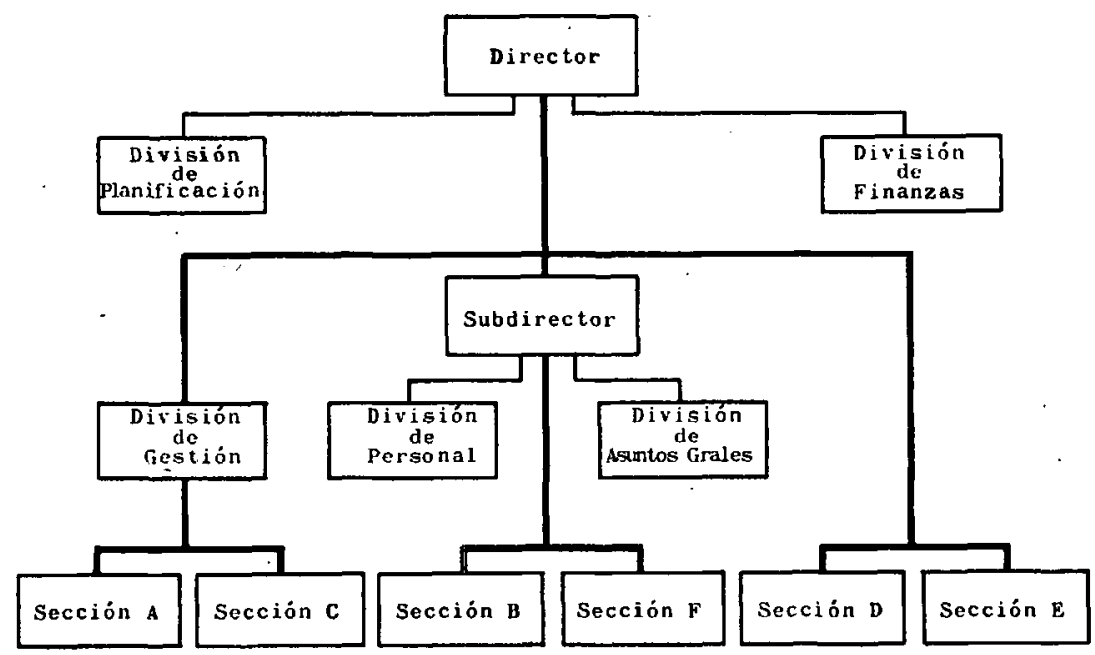

FIGURA 14

esquema oficial fuese el que recoge la figúra 15. La inclusión de aspectos informales en el gráfico obedece normalmente a la convicción de que es preferible representar la estructura tal cual es a elaborar un organigrama sin vigencia real. El riesgo que se deriva de ello consiste en que los gráficos ajustados a la situación de hecho pueden contribuir a consolidarla, preparando el terreno para su formalización indiscriminada. Por ello, a mi juicio, los organigramas deben limitarse en principio a reproducir la estructura oficial, bien entendido que tales representaciones raramente coincidirán con la realidad.

Para evitar ei efecto inmovilizador que para algunos puede derivarse de los organigramas oficiales, resulta conventente consignar siempre la fecha de confección, con lo cual se pone de manifiesto la transitoriedad del gráfico al tiempo que, llegado el caso, se facilita su actualización. 


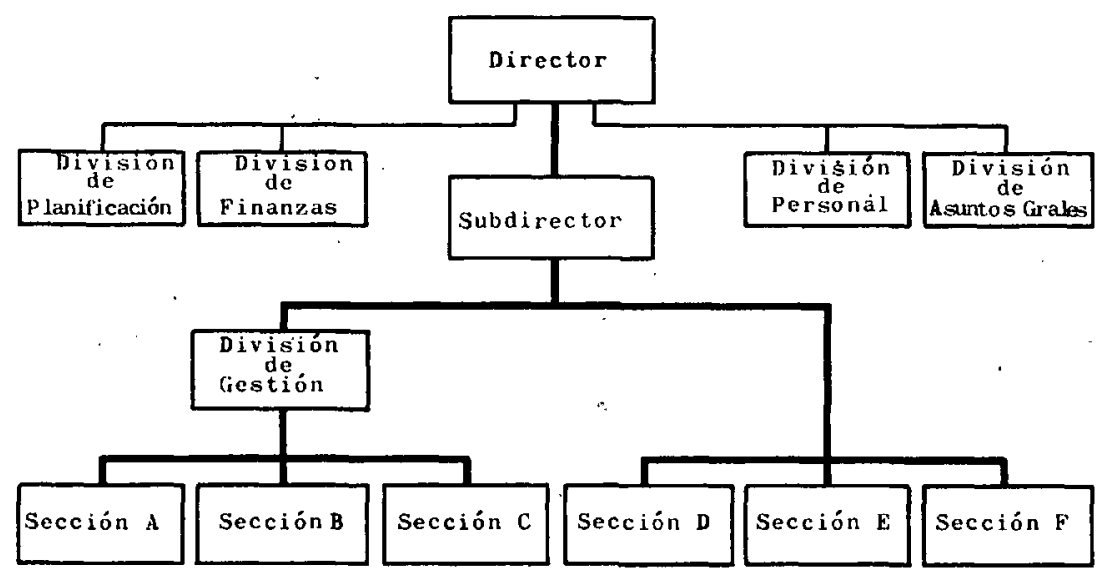

FIGGURA 15

Ciertos aspectos de hecho pueden ser excepcionaimente incorporados a un organigrama oficial cuando no desvirtúen este esquema. Asi, por ejemplo, unidades creadas formalmente pero no constituidas en la realidad, pueden figurar en recuadros de trazado discontinuo. acompañados de una indicación aclaratoria. Pero cuando la situación de hecho contradice abiertamente a la estructura formal (ruptura de niveles, interposiciones, aparición de relaciones de autoridad de facto, alteraciones de la dependencia orgánica, cortocircuito de jefaturas, sea de arriba abajo o de abajo arriba, etc.), es preferible proceder a representar separadamente la organización de hecho y la organización formal. Ello permite una comparación, siempre instructiva, de ambos esquemas, ya sea con fines analiticos o con cualquier otro propósito determinado.

\section{Conclusiones}

No parece necesario indicar que la relación precedente no agota, ni mucho menos, las incorrecciones y curiosidades gráficas que pueden encontrarse en la práctica. Como anomalías que también se registran con cierta frecuencia - sin añadir nuevos ejemplos que alargarian excesivamente estas notas - cabe señalar aqui las siguientes: 
Diferente desarrollo gráfico aplicado a sectores de idéntico nivel $y$ naturaleza

Algunos organigramas se presentan como simples agregaciones por yuxtaposición de gráficos distintos y confeccionados separadamente. En resultado (falta de uniformidad), dificulta la interpretación de los organigramas asi concebldos.

Inclusion de denominaciones de unidades $y$ de puestos dentro de un mismo nivel gráfico

Puede observarse en ciertos casos la mezcla de denominaciones dentro de un mismo escalón, de forma que al lado de epigrafes que recogen la designación completa de una unidad orgánica (Seccion de Personal), aparecen otras que prescinden del término genérico indicativo del rango (Contabilidad), o que se limitan, incluso, a sefalar una posición de jefatura dentro del mismo nivel (Jefe de Recursos). Como en el caso anterior, el resultado de tal desorden afecta directamente a la claridad del organlgrama.

Inclusion de servicios centrales y unidades periféricas en un mismo organigrama general, sin separación gráfica de zonas

Dada la dificultad de encuadrar las unidades periféricas en los mismos niveles previstos para recoger la estructura de los servicios centrales, no resulta conveniente elaborar representaciones conjuntas sin dividir el gráfico en dos zonas netamente separadas. Cuando tal división se omite la representación obtenlda suele ser, normalmente, inexacta.

Inclusión de organismos autónomos dentro del gráfico representativo de la organización jerarquizada.

Puede también registrarse en clertos casos el error consistente en insertar los organismos autónomos en la misma relación de autoridad-responsabilidad a que se vinculan los elementos que constituyen la organización jerarquizada. Dejando aparte la dificultad que entraña normalmente la resolución del problema de la asimilación de rango, una representación elaborada de este modo confunde la naturaleza del vínculo jerárquico con las relaciones de control y 
tutela, desfigurando al igual que en el caso anterior la organización que se pretende reflejar. La solución aconsejable consiste tambien en situar los organismos autónomos dentro de una zona ad hoc en la base del gráfico, sin entrar en el detalle de su estructura interna, que debe ser objeto de organigramas independientes.

\section{Desequilibrio gráfico del organigrama}

La primera finalidad que un organigrama se propone consiste, obviamente, en lograr una interpretación de la estructura aceptable en el fondo, aunque en ocasiones deba limitarse a recoger sus rasgos fundamentales. Sin embargo, dentro de esta exigencia de fidelidad, es conveniente obtener una representación armonica y equilibrada desde un punto de vista puramente gráfico. Ciertos organigramas presentan un aspecto innecesariamente asimétrico o inestable que produce la sensación de que la estructura de la entidad adolece de malformaciones que pueden no existir en la realidad. El juicio emitido por un alto funcionario, a la vista de cierto proyecto de organigrama, consistió en destacar su parecido con la torre de Pisa.

Como es altamente improbable que una elaboración de primera mano resulte plenamente satisfactoria en su aspecto material, parece aconsejable que, una vez resueltos los problemas de fondo, se proceda a una revisión del esquema atendiendo exclusivamente a su apariencia gráfica.

En definitiva, como muchas otras cosas, los organigramas llevan frecuentemente el sello inconfundible del trabajo improvisado e intuitivo. Cuando se opera de tal forma, sin experiencia anterior en el manejo de esta clase de gráficos o sin tomarse la molestia previa de adquirir la información indispensable, no puede esperarse que el resultado constituya un modelo de perfección técnica. El papel que corresponde jugar a la inspiracion en esta materia es realmente muy reducido. 
DA-1970, núm. 134. LUIS BLANCO DE TELLA. Precisiones sobre organigramas 